\title{
Pesquisa em Serviço Social e fundamentos da perspectiva teórico-metodológica marxiana
}

\author{
Adilson Aquino Silveira Júnior \\ Universidade Federal de Pernambuco (UFPE)
}

\section{Pesquisa em Serviço Social e fundamentos da perspectiva teórico-metodológica marxiana}

Resumo: Este artigo analisa o fundamento investigativo fornecido por Marx às suas categorias teórico-metodológicas, ou seja, como opera a relação entre ontologia, processo gnosiológico e método no pensamento do autor. Destaca que a apropriação da abordagem marxiana entre ontologia e método, no desenvolvimento da pesquisa em Serviço Social, constitui uma exigência para o aprofundamento da perspectiva crítica e emancipatória do projeto profissional. A partir da categoria da práxis, evidencia as vinculações orgânicas entre as determinações ontológicas e as metodológicas no processo de produção do conhecimento, que implicam a recusa de uma postura formal-abstrata. Finalmente, assinala que a perspectiva da totalidade concreta e da historicidade inviabiliza qualquer separação especulativa e formalista do método em relação às contradições da vida social.

Palavras-chave: Serviço Social. Práxis. Método. Processo cognoscitivo.

Research in Social Work and Foundations of the Marxian Theoretical-Methodological Perspective Abstract: This article analyzes the investigative foundation provided by Marx to his theoretical-methodological categories, that is, how to operate the relationship between ontology, gnosiological process and method in his work. It highlights that the appropriation of a Marxian approach to ontology and method in research in Social Work is necessary to deepen the critical and emancipatory perspective of the profession. Based on the category of praxis, it reveals the organic ties between the ontological and methodological determinations in the process of production of knowledge, which imply the refusal of a formal-abstract position. Finally, it indicates that the perspective of concrete totality and of historicity make unviable any speculative and formalist separation of the method in relation to the contradictions of social life.

Keywords: Social Work. Práxis. Method. Cognoscitive process. 


\section{Serviço Social e a perspectiva teórico- metodológica marxiana}

Inscrita no processo de "renovação do Serviço Social no Brasil", a perspectiva que se propõe como "intenção de ruptura" com o Serviço Social "tradicional" - conforme a pesquisa de Paulo Netto (2004) - adquire maturidade teórico-crítica para o tratamento da profissão no contexto da reprodução das relações sociais capitalistas quando incorpora a abordagem teórico-metodológica e crítico-dialética, haurida a partir de um trabalho sistemático sobre a fonte marxiana. Tal procedimento é apresentado pioneiramente na pesquisa de Marilda Iamamoto ${ }^{1}$. Calcada numa reflexão que se desdobra a partir dos textos marxianos fundamentais ${ }^{2}$, em que desenvolve a análise da instituição profissional no bojo da totalidade das relações sociais da ordem burguesa e na particularidade da formação social brasileira. Dentre as outras elaborações, construídas no marco do Serviço Social no contexto do processo de "intenção de ruptura", segundo Paulo Netto (2004), a análise de Iamamoto singulariza-se pela justa compreensão desenvolvida da postura teórico-metodológica marxiana. As resultantes dessa apreensão inflectem os rumos do debate profissional, qualifica-o teórica e politicamente, contribuindo de forma significativa para o desenvolvimento do chamado projeto ético-político do Serviço Social e influenciando a orientação teórico-metodológica assumida pelo mesmo. Em seus pressupostos, tal projeto evidencia uma apreensão da realidade sócio-histórica que identifica os processos de exploração, opressão e alienação como dimensões constitutivas da condição de classe do trabalho, típica da sociabilidade burguesa. No horizonte estratégico assumido, o projeto profissional vincula-se ao processo de superação do metabolismo social do capital através da construção de uma sociedade emancipada.

Não obstante tais avanços, o contexto atual é ainda marcado por tendências que fomentam o empirismo nas investigações, restringindo-as à "pseudoconcreticidade" do mundo fenomênico (KOSIK, 1976), e pela fragmentação da realidade social, o que alimenta o imediatismo nas análises, associadas aos enfoques limitados às esferas superestruturais. Permanecem as investigações que focalizam os segmentos alvos da intervenção profissional, e das políticas sociais, isolando o seu tratamento analítico das relações sociais que os constituem. Tais abordagens recebem impulso com a reprodução das concepções pós-modernas no âmbito da pesquisa social. Existe ainda uma fragilidade na apropriação da realidade estudada em sua relação com o movimento concreto das disputas hegemônicas entre as classes, o que proporciona o obscurecimento da conflitualidade social e do caráter antagônico do sistema imperante. Os problemas adensam=se com as dificuldades em desenvolver a pesquisa articulando teoria e método, cujo corolário é o recurso a uma lógica formal abstrata na definição das determinações metodológicas, mesmo no caso das abordagens da vertente crítico-dialética ${ }^{3}$.

Os ganhos apresentados com a abordagem desenvolvida no interior da perspectiva de "intenção de ruptura" podem ser aprofundados, ampliando suas contribuições no sentido de colmatar as lacunas existentes e solucionar os problemas que se apresentam na pesquisa em Serviço Social - considerando tanto os processos de investigação implicados na intervenção profissional, quanto aqueles estritamente vinculados à produção teórica - se for mantida e aperfeiçoada a postura, em face da obra marxiana, de determinação e incorporação de suas indicações metodológicas (e ontológicas) para a compreensão da realidade histórica. Desnecessário mencionar a centralidade e a importância estratégica - reafirmada em Iamamoto (2010) - que o exercício da pesquisa assume na formação e no exercício profissional no contexto do projeto ético-político, na atualização e formação de docentes e novas gerações de pesquisadores e na qualificação do exercício profissional ${ }^{4}$.

A direção social assumida pela profissão através do projeto ético-político demanda a crítica radical às pretensões, convergentes com o ponto de vista do capital - como nos mostra Mészáros (2009a) -, de neutralidade científico-epistemológica que implicam a tendência ao formalismo mistificador da conflitualidade social e da historicidade, inerentes ao sociometabolismo imperante. O exercício da pesquisa assume, portanto, o compromisso com a perspectiva e os interesses de classe dos trabalhadores e com sua emancipação das mais deletérias formas de degradação humano-social próprias da civilização do capital, intensificadas no contexto atual de "crise estrutural" (MÉSZÁROS, 2009b). Aqui cabe a lição que põe em relevo a reorientação marxiana do método, apresentada por Mészáros (2009a): a inseparabilidade entre os aspectos metodológicos e os problemas encontrados em sua dimensão substantiva, ou seja, o abandono de qualquer separação especulativa e formalista do método em relação aos aspectos complexos e contraditórios da vida social.

A incorporação da teoria social elaborada por Marx - e da perspectiva metodológica (dialética) imanente - constituiu (e constitui) um movimento fundamental para a reconstrução e o amadurecimento do quadro teórico-analítico sobre os fundamentos sócio-históricos da profissão, suas estratégias e práticas investigativas e interventivas, e para a reorientação da atuação política do corpo profissional e de suas entidades organizativas, no horizonte de um projeto emancipatório das classes subalternas. Assim, é imperativo prosseguir e aprimorar a apreensão dos fundamentos teórico-metodológicos 
marxianos para o avanço e a consolidação da perspectiva inaugurada naquela vertente do processo de renovação do Serviço Social que culminou no projeto ético-político. Aprofundar e ampliar a apropriação do legado marxiano, e da tradição que desenvolve e amplia suas contribuições, para pensarmos o Serviço Social e seu papel no tempo presente, constitui uma exigência histórica atual - conforme nos demonstra, de forma reiterada, Iamamoto (2004; 2006, 2010) e Paulo Netto (2004).

Embora reconheçamos a relevância de um tratamento detalhado sobre como Marx articulou, na sua teoria social, as categorias teórico-metodológicas imanentes ao objeto de estudo (totalidade, contradição, mediação, historicidade, particularidade etc.), precisamos abordar um fundamento intrínseco ao sentido mesmo da apreensão e do tratamento investigativo fornecido àquelas categorias: a concepção marxiana da relação entre ontologia, processo gnosiológico e método. Para tanto, recorreremos às análises de autores como Karel Kosik, István Mészáros, Adolfo Sanchez Vasquez, Georg Lukács, Antônio Gramsci, bem como à própria fonte marxiana, priorizando, por um lado, os manuscritos em que Marx assume a busca da sistematização de suas conclusões sobre o movimento do capital na sociedade burguesa - cujo resultado culmina nos primeiros esboços de construção da sua almejada crítica da economia política, dos quais são representativos os Grundrisse - e, por outro, os apontamentos que assumiram redação conclusiva em Contribuição à crítica da economia política, e em $O$ capital.

\section{Ontologia, atividade cognoscitiva e método: a práxis como fundamento}

A perspectiva de radicalidade que o pensamento marxiano imprime à investigação da vida social possui, como um dos elementos principais, a busca rigorosa da determinação da práxis humana, historicamente situada, na conformação da sociabilidade. A atividade humana, contudo, assume um caráter prático-objetivo a partir do qual e para o qual o conhecimento precisa orientar-se: "Todos os mistérios que conduzem à teoria e ao misticismo encontram sua solução racional na prática humana e na compreensão desta prática" (MARX, 2007, p. 534). Assim considerado, o ser social possui como determinação fundamental sua existência concreta. Marx (2008b, p. 46) identifica, na análise das "condições da vida material", a via que torna possível a solução dos problemas até então insolúveis quando levados a cabo por incursões analíticas que buscavam explicar o desenvolvimento das ideias jurídicas, políticas, filosóficas etc., como entidades autônomas (MÉZÁROS,
2008). Na orientação assumida, o critério de validade do conhecimento encontra-se na própria realidade histórico-social:

A questão de saber se ao pensamento cabe alguma verdade objetiva [gegenständliche Wahrheit] não é uma questão da teoria, mas uma questão prática. É na prática que o homem tem de provar a verdade, isto é, a realidade e o poder, a natureza citerior [Diesseitigkeit] de seu pensamento (MARX, 2007, p. 533).

A práxis, como atividade específica do ser social, constitui categoria heurística para a determinação da relação orgânica entre ontologia, processo gnosiológico e método. Como nos mostra Kosik (1976, p. 221), a problemática da práxis na filosofia materialista emerge como resposta filosófica ao problema filosófico: "quem é o homem, o que é a sociedade humano-social, e como é criada essa sociedade?". No conceito de práxis a realidade humanosocial se desvenda como formadora e, ao mesmo tempo, como forma específica do ser humano. A práxis é a esfera do ser humano: o conceito de práxis põe em evidência o autêntico caráter da criação humana como realidade ontológica ${ }^{5}$ (KOSIK, 1976). No curso dessa "atividade propriamente humana", Vázquez (2007) nos mostra que os atos dirigidos à transformação de um determinado objeto se iniciam como um resultado ideal, um fim, e culminam num resultado ou produto efetivo. Esse processo implica a intervenção da consciência, pois a "atividade humana" não pode prescindir da formulação de um resultado ideal, de um fim a cumprir, como ponto de partida. Do mesmo modo, exige também uma intenção de adequação, independentemente de como o modelo ideal originário apresente-se plasmado. O fim postulado na consciência durante a atividade humana se sujeita, assim, ao curso da própria atividade e às causalidades presentes na interação com a realidade. Essa atividade consciente que rege a produção dos fins não provém, no entanto, de uma consciência pura, mas da consciência de um homem social em sua historicidade.

Segundo Vázquez (2007), além da prefiguração ideal do resultado real pretendido, a atividade humana que se desdobra como produção de fins manifesta-se também como produção de conhecimento - na forma de conceitos, hipóteses, teorias ou leis mediante as quais o sujeito conhece a realidade que pretende transformar. Os fins que a consciência produz carregam a exigência de realização que pressupõe, entre outras condições, uma atividade cognoscitiva sem a qual os mesmos não poderiam realizar-se. A atividade da consciência, inerente à "atividade propriamente humana", constitui-se de elaboração de fins e produção de conhecimentos em íntima unidade. Com isso, as finalidades postas pela atividade 
teleológica (produção de fins) são acompanhadas de uma vontade de realização que requer um conhecimento de seu objeto, dos meios e instrumentos para transformá-lo e das condições que possibilitam essa realização: "As atividades cognoscitiva e teleológica da consciência se encontram em uma unidade indissolúvel" (VÁZQUEZ, 2007, p. 225).

Seguindo as indicações marxianas, Vázquez (2007) considera que na "atividade prática" o objeto da atividade existe independentemente da consciência e das diferentes operações e manipulações exigidas para sua transformação pelo sujeito; e seu produto constitui um objeto material que adquire uma substancialidade própria, ou seja, adquire vida independente da atividade subjetiva que o criou. A atividade teórica somente existe por e em relação com a prática, pois nela encontra seu fundamento, seus fins e critério de validade, mas não é uma forma de práxis, pois lhe falta aquele lado material, objetivo. O objeto ou matéria-prima da atividade teórica entendida como a produção de fins (teleologia) e de conhecimento (cognoscitiva) - são as sensações ou percepções - objetos psíquicos que apenas possuem uma existência subjetiva - ou os conceitos, teorias, representações ou hipóteses que têm uma existência ideal. A finalidade imediata da atividade teórica é elaborar ou transformar, no plano ideal, aquela matéria subjetiva para obter, como produtos, teorias que expliquem a realidade presente, ou modelos que prefigurem idealmente uma realidade futura. Vázquez (2007) conclui que a atividade teórica oferece um conhecimento indispensável para a transformação da realidade, ou para a prefiguração dos fins que antecipem, no nível subjetivo, sua transformação, mas, em ambos os casos, a realidade objetiva permanece intacta. As transformações realizadas são transformações ideais, de ideias sobre o mundo, mas não do próprio mundo.

$\mathrm{Na}$ crítica ao idealismo, que considerava a atividade especulativa como ato de produção efetiva do mundo, Marx (2011, p. 55) mostra-nos a importância da atividade teórica (e o papel ativo do sujeito) para a reprodução ideal da sociedade como uma totalidade concreta, mas, ao mesmo tempo, acrescenta as razões dos equívocos especulativos e os limites teóricos dessa atividade mesma:

[...] para a consciência para a qual o pensamento conceitualizante é o ser humano efetivo, e somente o mundo conceituado enquanto tal é o mundo efetivo - e a consciência filosófica é assim determina$\mathrm{da}-$, o movimento das categorias aparece, por conseguinte, como o ato de produção efetivo - que, infelizmente, recebe apenas um estímulo do exterior -, cujo resultado é o mundo efetivo; e isso que, no entanto, é uma tautologia - é correto na medida em que a totalidade concreta como totali- dade do pensamento, é de fato um produto do pensar, do conceituar; mas de forma alguma é um produto do conceito que pensa por fora e acima da intuição e da representação dos conceitos. O todo como um todo de pensamentos, tal como aparece na cabeça, é um produto da cabeça pensante que se apropria do mundo do único modo que lhe é possível, um modo que é diferente de sua apropriação artística, religiosa e prático-sensível.

Nesses termos, Kosik (1976) considera que a práxis, na sua essência e universalidade, é a revelação do segredo do homem enquanto ser ontocriativo, que cria a realidade (humano-social) e que, portanto, compreende a realidade (humana e não humana), na sua totalidade. A práxis não se apresenta como atividade prática contraposta à teoria, mas é determinação da existência humana como elaboração da realidade. Através dela ocorre abertura do homem para a realidade em geral, nela se baseiam as possibilidades de uma ontologia, de uma compreensão do ser. A criação da realidade humano-social constitui o pressuposto para a abertura e a compreensão da realidade em geral, sendo esse um processo essencial. Na práxis se apresenta a abertura do homem diante da realidade e do ser. Esse autor (1976, p. 226) acrescenta que "[...] na práxis se descobriu o fundamento do real centro da atividade, da real mediação histórica de espírito e matéria, de cultura e natureza, de homem e cosmos, de teoria e ação, de ente e existente, de epistemologia e ontologia". O conhecimento do mundo, das coisas, dos processos, apenas nos é possível na medida em que os reproduzimos espiritual e intelectivamente. Essa reprodução intelectiva apenas pode ser concebida como um dos muitos modos de relação prático-humana com a realidade, cuja dimensão mais essencial é a criação da realidade humano-social. Assim, a compreensão das coisas e do seu ser, do mundo dos fenômenos particulares e da totalidade, torna-se possível para o ser humano a partir da "abertura que eclode na práxis" (KOSIK, 1976, p. 227).

De acordo com Mészáros (2009a), na abordagem de Marx, a solução tanto para os mistérios especulativos da filosofia idealista quanto para todos os problemas e as contradições aparentemente intratáveis da ordem social deve ser buscada através de uma reorientação radical do próprio pensamento, em contraste com as preocupações filosóficas do passado. Foi preciso encontrar uma forma de abordagem distinta ao adotar-se a "mundaneidade do pensamento" (MARX, 2007), na qual toda investigação teórica deve estar orientada para a prática transformadora relevante aos seus interesses. Assim, a ideia de unificar teoria e prática assume uma importância fundamental na concepção marxiana do mundo, permanecendo como um de seus princípios orientadores vitais (MÉSZÁROS, 2009a). 
As questões que perpassam a atividade teórica são orientadas para a determinação das relações orgânicas presentes na práxis humana entre realidade prático-objetiva e representação ideal. É nesses termos que se assenta a abordagem analítica dos problemas acerca da perspectiva metodológica em Marx. Em sua obra, as reflexões de ordem metodológica não se encontram autonomizadas do objeto da investigação ${ }^{6}$, ou seja, o campo epistemológico é intrínseco à direção ontológica da reflexão. Por isso, o interesse não incide sobre um abstrato "como conhecer?", mas sobre "como conhecer um objeto determinado", tal como Lênin, nos seus Cadernos Filosóficos, indica: "Se Marx não nos deixou uma Lógica (com um grande L), nos deixou a lógica de $O$ capital" (LENIN, 1976 apud BENOIT, 1999, p. 82).

Duas considerações de importância central, apresentadas por Paulo Netto (2011), devem ser destacadas, portanto: primeiro, para Marx, o método não consiste num conjunto de regras formais que se "aplicam" a um objeto que foi recortado para uma investigação determinada, ou escolhida pelo pesquisador, conforme a sua vontade, para "enquadrar" o seu objeto de investigação ${ }^{7}$; segundo, e em decorrência da assertiva anterior, a indissociável conexão entre epistemologia e ontologia na obra de Marx impede uma abordagem que autonomize $o$ método em face da teoria, de modo que não é possível analisar sua abordagem metodológica sem a necessária referência à teoria desenvolvida e, da mesma forma, a teoria social em tela torna-se ininteligível sem a apreensão de seu método.

A interpretação lukacsiana ${ }^{8}$ da perspectiva de Marx indica o método como sistematização - a elevação para-si das experiências com o desconhecido, que se originam da necessidade de desvelamento do real, intrínseca à práxis humana. À reflexão metodológica compete sempre sob condições histórico-sociais determinadas fornecer a maneira pela qual podemos enfrentar eficientemente o objeto (parte do real a ser investigada e, portanto, ainda desconhecida) de modo a convertê-lo em elemento potencializador da práxis humana. Assim, possibilita determinar a relação mais adequada a partir da qual o sujeito pode apreender e reproduzir, no plano ideal, o movimento do objeto pesquisado, considerando o acúmulo de conhecimentos e as experiências existentes. O método exibe uma definição ontológica fundante: seu ser é determinado pelas exigências da própria realidade. Por isso mesmo os requisitos metodológicos fundamentais de Lukács (1981), na Ontologia do ser social, decorrem de suas categorias ontológicas centrais. A particularidade do procedimento metodológico encontra na ontologia seu fundamento último (LESSA, 1995, 1999, 2000). Nos apontamentos de Gramsci (2011, p. 122), em seus escritos carcerários, encontramos as mesmas indicações, na seguinte passagem:

\section{[...] deve-se deixar estabelecido que toda investi- gação tem seu método determinado e constrói uma ciência determinada, e que o método desenvolveu- se e foi elaborado conjuntamente ao desenvolvi- mento e à elaboração daquela determinada investi- gação e ciência.}

Por essa via, são as determinações do objetivo investigado que indicam e fornecem a relação e os procedimentos mais adequados para o seu desvelamento. A esfera ontológica - as determinações do objeto - orienta a metodologia. Como decorrência, Lessa (1999) acrescenta que a metodologia mais adequada ao conhecimento de um objeto dado apenas pode ser delimitada com precisão post festum, ou seja, após o pesquisador ter-se apropriado das determinações do objeto. Isso não oblitera, entretanto, o importante papel que possui a reflexão metodológica para a investigação da realidade, pois previsões e antecipações acerca do método mais adequado à determinada investigação podem ser desenvolvidas a partir dos conhecimentos produzidos pelas experiências com objetos que parecem semelhantes, ou que ocupam os mesmos complexos da sociabilidade em estudo.

$\mathrm{Na}$ perspectiva marxiana, portanto, uma determinação metodológica para a investigação da realidade se apresenta, em primeiro lugar, como resposta à pergunta: o que é a realidade? Apenas em segundo lugar, e como consequência da solução ontológica à questão anterior, aquela determinação pode constituir um princípio 
epistemológico e uma exigência metodológica. Essa relação entre método e ontologia é sintetizada por KOSIK, (1976, p. 43): “A questão: como se pode conhecer a realidade? é sempre precedida por uma questão mais fundamental: que é a realidade?".

As indicações lukacsianas, desenvolvidas a partir da obra de Marx, informam que consciência e objetividade são processualidades históricas. A relação entre ambas não se esgota, de modo que o movimento constitutivo de cada uma impossibilita qualquer relação de identidade sujeito-objeto. O estudo de Lessa $(1995,1999,2000)$, sobre a obra madura de Lukács, aponta que o conhecimento constitui o processo de aproximação, historicamente determinado, da consciência ao "ser-em-si", embora tal processo não implique a postulação da identidade sujeito-objeto. Por outro lado, o insuperável caráter de aproximação do processo gnosiológico não significa que apenas o conhecimento do real, em suas dimensões singulares e parciais, pode ser alcançado. Ou seja, não significa que a totalidade seja uma dimensão interdita à consciência, pois, através da práxis os homens têm acesso tanto aos aspectos e determinações parciais, quanto às categorias mais universais do "ser-precisamente-assim" existente, considerado como síntese de múltiplas determinações. O processo de aproximação da consciência ao real diz respeito, de forma concomitante, às dimensões universais e às particularidades dos objetos envolvidos. O caráter aproximativo do processo gnosiológico não conduz à afirmação da incognoscibilidade da totalidade. A relação entre ontologia e gnosiologia na elaboração teórico-metodológica em tela

\section{[...] permite reconhecer a falta de homogeneidade e correspondência entre estrutura lógica (modelo) por meio da qual se explica a realidade - ou melhor, uma determinada secção da realidade - e a estrutura dessa mesma realidade. Mediante um determinado modelo (que estruturalmente é de 'ordem inferior' comparado à estrutura de uma determinada região do real) esta só pode ser interpretada de modo apro- ximativo, sendo o modelo apenas uma primeira apro- ximação de uma adequada descrição e interpreta- ção da realidade (KOSIK, 1976, p. 47).}

Do mesmo modo, também na reflexão metodológica o caráter de aproximação de todo movimento gnosiológico é evidenciado. A partir de um novo avanço do conhecimento, ampliam-se as experiências de investigação que poderão (e deverão) ser generalizadas em sentido metodológico. Para Lessa (1999), em um grau maior de generalidade, é possível alcançar algumas indicações metodológicas fundadas na sistematização das experiências existentes que orientem, a priori, quais aquelas abstrações, dentre as que se apresentam no contexto de uma inves- tigação, mais apropriadas para o conhecimento do objeto, embora a efetividade destas na apropriação do real apenas possa ser constatada post festum. Os procedimentos metodológicos, porquanto busquem orientar a postura do sujeito cognoscente face ao desconhecido, sustentam-se na sistematização das determinações ontológicas mais gerais alcançadas a cada momento histórico, de modo que o conhecimento adquirido constitui o fundamento das indicações metodológicas para as investigações seguintes ${ }^{9}$. As relações de determinação recíproca entre ontologia e método, que implicam a recusa de qualquer postura formal-abstrata na definição das indicações metodológicas para o desvelamento da realidade sócio-histórica, levam Marx (2008a,p. 31) a evidenciar que "Não há estrada real para a ciência, e só tem probabilidade de chegar a seus cimos luminosos aqueles que enfrentam a canseira de galgá-los por veredas abruptas".

Tal processo, no entanto, não é regido por qualquer neutralidade científico-epistemológica. Encontra-se mediado (nas sociedades de classe) pelas disputas presentes entre os sujeitos envolvidos na dinâmica sociorreprodutiva. No metabolismo social do capital, tais sujeitos ocupam posições no interior das classes e segmentos de classe com interesses divergentes e antagonistas. Não é secundário, portanto, o papel ocupado pela ideologia - como um conjunto de concepções que permitem aos diferentes grupos e classes sociais se organizarem para luta pela hegemonia - na definição das perspectivas metodológicas assumidas. De acordo com Lessa (1995), o complexo (dinâmico) da metodologia não constitui um campo hipostasiado da dinâmica metabólico-social, apenas possui existência concreta em intrínseca determinação reflexiva tanto com a ontologia, como com a ideologia e, por meio dela, com a política, a filosofia, a moral, a ética etc. Paulo Netto (2011) conclui que a relação sujeito/objeto no processo do conhecimento teórico não é marcada por qualquer externalidade, antes, é uma relação na qual o sujeito está implicado no objeto, de modo que a pesquisa - e a teoria que dela resulta - sobre a sociedade exclui as pretensões de "neutralidade", em geral identificadas com "objetividade". A própria construção da abordagem teórico-metodológica marxiana pode ser entendida somente em sua inserção na luta de classes, como crítica representativa da "voz de uma classe [...] cuja missão histórica é derrubar o modo de produção capitalista e abolir, finalmente, todas as classes: o proletariado" (MARX, 2008a, p. 25).

\section{Historicidade, totalidade e perspectiva revolucionária}

A determinação social do método assumida pela crítica revolucionária desenvolvida por Marx ori- 
enta-se, segundo Mészáros (2009a), na direção contrária ao procedimento que consiste em eternizar as relações de troca do sociometabolismo do capital e estabelecer o culto do indivíduo isolado em consonância com esses elementos. A reorientação marxiana do método põe ainda em relevo a inseparabilidade dos aspectos metodológicos dos problemas encontrados em sua dimensão substantiva. Desse modo, considerando a própria necessidade de transformação intransigente da ordem social estabelecida em sua totalidade, Mészáros (2009a) observa que a definição marxiana da ciência assume uma inseparabilidade da mais radical intervenção prática no curso das mudanças qualitativas envolvidas, indicando que qualquer explicação teórica isolada não poderia oferecer as soluções requeridas nesse âmbito. Por outro lado, para Marx, tampouco é suficiente dedicar-se apenas à negação da ordem dada. Tal negação precisa ser combinada com a demonstração da viabilidade histórica da ordem hegemônica alternativa, positiva, e necessária, personificada em um movimento emancipatório social globalmente progressivo: a defesa da unidade entre teoria e prática "tornou absolutamente claro que a prática revolucionária, no sentido mais óbvio de seus termos de referência, teria de assumir o papel central na concepção marxiana de ciência" (MÉSZÁROS, 2009a, p. 214).

A orientação metodológica fundamental da abordagem marxiana, fundada na perspectiva ontológica da totalidade concreta, foi resumida nos seguintes termos: "conhecemos uma única ciência, a ciência da história". Mais ainda, "A história pode ser examinada de dois lados, dividida em história da natureza e história dos homens. Os dois lados não podem, no entanto, ser separados; enquanto existirem homens, história da natureza e história dos homens se condicionarão reciprocamente" (MARX, 2007, p. 86).

Não surpreende, portanto, o fato de que Marx tenha rejeitado com veemência a ideia de que vários domínios da atividade intelectual humana deveriam constituir campos teóricos autônomos e voltados para si mesmos, com critérios de investigação histórica opostos de maneira artificial (MÉSZÁROS, 2009a). Na concepção marxiana, "Não há história da política, do direito, da ciência etc., da arte, da religião etc." (MARX, 2007, p. 77), todos esses campos precisam ser investigados como partes integrantes de um todo coerente. O próprio Gramsci (2011, p. 166) havia indicado essa perspectiva, nos Cadernos do cárcere, quando se pergunta se a "filosofia da práxis" não seria uma teoria da história: "ao que se responde que isto é verdade, mas que é impossível, por isso mesmo, destacar da história a política e a economia, mesmo em suas fases especializadas, de ciência e arte da política e de ciência e política econômica".
Destarte, a solução dos mistérios da "magia do dinheiro" que assume a forma de "enigma do dinheiro" inseparável do "enigma da mercadoria" (MARX, 2008a) na produção generalizada de mercadorias, requereu a adoção do método que apreendesse a particularidade do sociometabolismo vigente, remetida à gênese abrangente da totalidade sócio-histórica. A questão central a ser resolvida era acerca da differentia specifica da forma valor. Apenas no interior do desenvolvimento da estrutura socioeconômica mais avançada na história, e correspondentemente multifacetada, tornar-se-ia possível localizar as respostas aos "enigmas" indicados. Esse posicionamento sustenta-se no princípio metodológico de que "a anatomia do ser humano é uma chave para a anatomia do macaco" (MARX, 2011, p. 58), e não o contrário, ou seja, que a forma mais elevada de desenvolvimento inaugura a possibilidade de explicar as menos avançadas. Para Mészáros (2009a), os "enigmas" enfrentados não podiam ser elucidados sem uma análise histórica abrangente do desenvolvimento humano que investigasse a relação metabólica entre a humanidade e a natureza, assim como dos indivíduos entre eles mesmos, em seu terreno objetivo de determinação, ou seja, na moderna sociedade burguesa. A investigação assim orientada é, de maneira simultânea, ontológico-social e histórico-genética. A abordagem em questão implica uma análise da differentia specifica que, de forma constante, evidencia a totalidade do desenvolvimento sócio-histórico levando à fase mais avançada através da demonstração de sua gênese abrangente, enquanto incorpora em seus resultados explicativos também as características definidoras relevantes das fases anteriores.

Assim, esses apontamentos nos possibilitam no espaço do artigo - indicar alguns fundamentos da orientação teórico-metodológica da crítica marxiana que podem contribuir para o tratamento das problemáticas concernentes à pesquisa em Serviço Social. Essa tarefa demanda sua continuidade através de trabalhos que desenvolvam, de forma mais específica, a articulação entre os fundamentos evidenciados e as questões particulares que perpassam essas problemáticas. As lições extraídas requisitam a superaração das tendências empiristas e imediatistas através da perspectiva da totalidade concreta e da historicidade. Também o aperfeiçoamento da articulação entre reprodução ideal dos objetos estudados e as determinações metodológicas específicas. Além disso, deve corroborar a necessidade da construção de vínculos orgânicos entre as investigações concretas (incluindo a orientação metodológica assumida) e as disputas hegemônicas das classes subalternas no contexto atual.

Sabemos que o aprimoramento das questões metodológicas no âmbito da pesquisa, orientado pela perspectiva crítico-dialética, assumiu e assume um 
papel estratégico na superação do conservadorismo profissional. O avanço do projeto ético-político do Serviço Social e a superação dos seus desafios contemporâneos ${ }^{10}$ exigem que a categoria profissional prossiga com a apropriação da obra marxiana, desenvolvendo-a, tanto no que consiste ao tratamento das suas categorias teóricometodológicas, quanto à determinação da relação existente entre ontologia, como processo gnosiológico e método. Nesse sentido, os elementos teóricos fornecidos em nosso artigo sinalizam que as determinações metodológicas mais fecundas da obra de Marx, para a pesquisa e a atuação do Serviço Social no tempo presente, são ininteligíveis como indicações metodológicas autônomas, ou regras formais aplicáveis indiferentemente aos processos investigativos concretos. $\mathrm{O}$ trabalho de apreensão e aprofundamento dos elementos presentes na elaboração marxiana requer o esclarecimento das vinculações existentes entre essa teoria social e as categorias metodológicas correspondentes, assumindo os fundamentos constitutivos de uma postura teórico-metodológica que possibilita ao pesquisador "pensar por sua própria conta” (MARX, 2008a, p. 16).

\section{Referências}

ABESS-Associação Brasileira de Ensino de Serviço Social. Cadernos ABESS, São Paulo: Cortez, n. 6, 1998.

BARROCO, M. L. S. Barbárie e neoconservadorismo: os desafios do projeto ético-político. Serviço Social \& Sociedade, São Paulo: Cortez, n. 106, p. 205-218, abr./jun. 2011.

BRAZ, M. A Hegemonia em xeque: Projeto Ético-Político do Serviço Social e seus elementos constitutivos. Revista Inscrita, Brasília: Cfess, n. 10, p. 5-10, 2007.

BENOIT, H. Pensando com (ou contra) Marx? Sobre o método dialético de 'O capital'. Revista crítica marxista, São Paulo: Unicamp, n. 8, p. 81-92, 1999.

GRAMSCI, A. Cadernos do cárcere. Tradução de Carlos Nelson Coutinho com a colaboração de Luiz Sergio Henriques e Marco Aurélio Nogueira. Rio de Janeiro: Civilização Brasileira, 2011. (v. 1).

IAMAMOTO, M. V. Renovação e conservadorismo no Serviço Social. São Paulo: Cortez, 2004.

O Serviço Social na contemporaneidade: trabalho e formação profissional. São Paulo: Cortez, 2006.

Serviço Social em tempo de capital fetiche: ca-pital financeiro, trabalho e questão social. São Paulo: Cortez, 2010.
IAMAMOTO, M. V.; CARVALHO, R. Relações sociais e Serviço Social no Brasil: esboço de uma interpretação históricometodológica. São Paulo: Cortez, 2005.

KOSIK, K. Dialética do concreto. Tradução de Célia Neves e Alderico Toríbio. Rio de Janeiro: Paz e Terra, 1976.

LESSA, S. El método y su fundamento ontológico. 2000. Disponível em: <http://www.sergiolessa.com/Cap de livros/ Lkcs metod cap -2000.pdf >. Acesso em: 2 jul. 2011.

Lukács, ontologia e método: em busca de um(a) pesquisador(a) interessado(a). 1999. Disponível em: 〈http:// www.sergiolessa.com/artigos 97 01/metodo ontologia 1999.pdf $>$. Acesso em: 2 jul. 2011.

Lukács: método e ontologia. 1995. Disponível em: <http:/ /www.sergiolessa.com/artigos 92 96/metodo ontologia 1995.pdf>. Acesso em: 2 jul. 2011.

LUKÁCS, G. Per l'ontologia dell'essere sociale. Tradução de Alberto Scarponi. Roma: Riuniti, 1981. (v. I, II e III).

MARX, K. Ideologia alemã. Tradução de Rubens Enderle, Nélio Schneide e Luciano Cavini Martorano. São Paulo: Boitempo, 2007.

O capital: O processo de produção do capital. Tradução de Reginaldo Sant'Anna. Rio de Janeiro: Civilização Brasileira, 2008a.

Contribuição à crítica da economia política. Tradução de Florestan Fernandes. São Paulo: Expressão Popular, 2008b.

Grundrisse: manuscritos econômicos de 1857-1858: esboços da crítica da economia política. Tradução de Mario Duayer. São Paulo: Boitempo, 2011.

MÉSZÁROS, I. Estrutura social e formas de consciência: a determinação social do método. Tradução de Luciana Pudenzi, Francisco R. Cornejo e Paulo Cezar Castanheira. São Paulo: Boitempo, 2009a.

Para além do capital: rumo a uma teoria da transição. Tradução de Paulo Cezar Castanheira e Sergio Lessa. São Paulo: Boitempo, 2009b.

Marxismo e direitos humanos. In: Filo-sofia, ideologia e ciência social. Tradução de Ester Vaisman. São Paulo: Boitempo, 2008, p. 157-168.

PAULO NETTO, J. Relendo a teoria marxista da história. In: SEMINÁRIO NACIONAL DE ESTUDOS E PESQUISAS HISTÓRIA, SOCIEDADE E EDUCAÇÃO NO BRASIL, IV, 1997. Disponível em: <http://www. histedbr.fae.unicamp.br/ acer histedbr/seminario/seminario4/trabalhos/mesa06.rtf $>$. Acesso em: 12 dez. 2011. 
A construção do projeto ético-político do Serviço Social frente à crise contemporânea. In: CFESS-ABEPSS. Capacitação em Serviço Social e política social: Crise contemporânea, questão social e Serviço Social, módulo 1. Brasília: CEAD, 1999.

Ditadura e Serviço Social. São Paulo: Cortez, 2004.

Palestra de abertura. In: ENCONTRO NACIONAL DE PESQUISADORES EM SERVIÇO SOCIAL, XI. São Luís, dez. 2008.

Introdução ao estudo do método em Marx. São Paulo: Expressão Popular, 2011.

REVISTA KATÁLYSIS. Pesquisa em Serviço Social. Florianópolis: Edufsc, número especial 2007.

SETÚBAL, A. A. Pesquisa em Serviço Social: utopia e realidade. São Paulo: Cortez, 2005.

VÁZQUEZ, A. S. Filosofia da práxis. São Paulo: Expressão Popular, 2007.

\section{Notas}

1 Esse trabalho encontra-se integralmente na Dissertação de Mestrado de Iamamoto, Legitimidade e crise do Serviço Social: um ensaio de interpretação sociológica da profissão, de 1983, em parte publicada em Iamamoto e Carvalho (2005), cuja primeira edição data de 1982.

2 Com destaque para $O$ capital (MARX, 2008a), inclusive incorporando o inédito capítulo VI, mas recorrendo ainda ao Grundrisse (MARX, 2011). Também com o aporte de autores como Gramsci, Lefebvre, Lênin, Poulantzas.

3 Essa problemática é tratada nos Cadernos ABESS (1998), no número especial da Revista Katálysis (2007) e em Iamamoto (2010). Também em palestra proferida por Paulo Netto (2008).

4 A discussão acerca da importância da pesquisa adquire fôlego nos anos 1990, tanto com pesquisadores individuais, comoé o caso do trabalho de Setúbal (2005), quanto pelos debates da organização acadêmico-política da profissão, comonos revela o material publicado no já citado Caderno ABESS (1998).

5 De acordo com Lessa (2000), o fundamento ontológico do processo de conhecimento radica-se na práxis social e, dentro desta, mais especificamente, no trabalho enquanto categoria fundante do mundo dos homens.

6 Segundo Paulo Netto (1997), o fato de o interesse epistemológico estar sempre subordinado à direção ontológica da reflexão, levou Marx a se deter em pouquíssimos momentos numa discussão estritamente metodológica. Quando Marx discute método, o faz sempre relacionando à um objeto preciso.
7 Paulo Netto (2011) nos indica, também, que os instrumentos e as técnicas de pesquisa não podem ser identificados com o método, mesmo porque instrumentos/técnicas similares podem servir, em escala variada, a concepções metodológicas diferentes.

8 Nossa referência são as indicações sobre método da Ontologia do ser social, de Georg Lukács (1981), aportando-nos às sistematizações de Lessa $(1995,1999,2000)$.

9 Como consequência, o método assume uma dimensão de particularidade; um objeto situado requer um método particular para ser conhecido. Para Gramsci (2011, p. 235): "não existe ciência por excelência e não existe método por excelência, 'um método em si'. Toda pesquisa científica cria para si um método adequado, uma lógica própria, cuja generalidade e universalidade consistem apenas em ser "conforme ao fim"”.

10 Os atuais desafios ao projeto ético-político são indicados por Paulo Netto (1999), Braz (2007) e Barroco (2001).

\section{Adilson Aquino Silveira Júnior}

j_r1987@hotmail.com

Mestrando em Serviço Social pelo Programa de PósGraduação em Serviço Social da Universidade Federal de Pernambuco (PPGSS-UFPE)

\section{PPGSS - Universidade Federal de Pernambuco} Av. Prof. Moraes Rego, 1235

Cidade Universitária

Recife - Pernambuco

CEP: 50670-901 